\title{
THE PERSONAL SIGNIFICANCE OF THE HUMAN BODY IN WOJTYLA'S PHILOSOPHY OF THE HUMAN PERSON
}

\section{Bai Ziqiang Chinese University of Hong Kong, Hong Kong}

\begin{abstract}
The human body has always been a fascinating object of investigation throughout human history. Indeed, as a topic, the human body encompasses almost the totality of human concerns. It can be examined in various contexts and from multiple points of view. In fact, the human body has been treated from so many diverse standpoints that it seems no longer able to be considered from a particular broader perspective as a sing subject matter. In Karol Wojtyla's philosophy of the human person, however, a particular broader perspective of the body is possible and also necessary. The human body for Wojtyla is not completely reducible as a specific object of investigation. As a part of the whole that is the human person, the human body is also something that is irreducible, i.e., with a personal significance. Without acknowledging the body's personal significance, the different considerations of the body are without a particular broader perspective and thereby easily lapse to be considerations not of the human body but a specific organism. This paper intends to explore the body's personal significance in Wojtyla's philosophy of the human person. Specifically, this paper proceeds in two steps, first Wojtyla's understanding of the human person is presented, and then his analysis of the human body as personal.
\end{abstract}

\section{INTRODUCTION}

The human body has always been a fascinating object of investigation throughout human history. This interest is well attested by a famous book published in 2013, The Body in History: Europe from the Palaeolithic to the Future. In fact, in recent years, the human body is catching renewed attention as "a popular and perhaps even fashionable topic" (Diemling and Giuseppe 2009, 1). However, it might be re-asked as Caroline Walker Bynum $(1995,2)$ already did, "why all the fuss about the body?" No exact answer can be offered, for, as already pointed out by her $(1995,2)$, "[i]n a sense of course, 'the body' is the wrong topic. It is no topic or, perhaps, almost all 
topics." Indeed, as a topic, the human body encompasses almost the totality of human concerns. It can be examined in various contexts and from multiple perspectives (See Diemling and Giuseppe 2009, 1). Thus, Bynum is utterly right in remarking that the human body in itself is paradoxically a "wrong" topic. It becomes an acceptable topic only within a specific context and a particular understanding. In effect, a particular broader perspective of the body is hardly possible.

In Karol Wojtyla's philosophy of the human person, however, a particular broader perspective of the body is possible and also necessary. Wojtyla $(1979,203)$ warns, "we cannot discuss the human body apart from the whole that is man, that is, without recognizing that he is a person. Neither can we examine the dynamisms and potentialities proper to the human body without understanding the essentials of action and its specifically personal character." Put differently, the human body is not entirely reducible as a specific object of investigation. As a part of the whole that is the human person, the human body is also something that is irreducible, i.e., something with a personal significance. Without acknowledging the body's personal significance, the different considerations of the body are without a certain larger or common perspective, and thereby easily lapse to be considerations not of the human body but a specific organism. This paper intends to explore the body's personal significance in Wojtyla's philosophy of the human person. Specifically, this paper proceeds in two steps, first Wojtyla's understanding of the human person is presented, and then his analysis of the human body as personal.

\section{WOJTYLA'S UNDERSTANDING OF THE HUMAN PERSON}

Inheriting from both Aristotelian Thomism and Schelerian Phenomenology, Wojtyla's philosophy of the human person intends to fuse together the subjectivity of the human person in the metaphysical terms of suppositum and the subjectivity of the human person in the phenomenological terms of experience. These twofold subjectivities, for Wojtyla, make up the one personal/total subjectivity. In general, Wojtyla (1993a, 212) considers his philosophy of the human person as first having Aquinas' inheritance of the Boethian definition of person, i.e., the human person as a suppositum, as its "metaphysical terrain"; second having the "experience of man" as the very entrance of its investigation; and accordingly, third having phenomenological description as its primary method of investigation.

Faithful to his phenomenological method of investigation, Wojtyla $(1979,4)$ takes the empirical standpoint and contends that experience is the origin of human cognition, and all one may know of himself/herself is "ultimately grounded in experience." Accordingly, the twofoldness of man's personal subjectivity is immediately revealed in experience. Wojtyla (1993b, 221) writes:

In the field of experience, the human being appears both as a particular suppositum and as a concrete self, in every instance unique and unrepeatable. This is an experience of the human being in two senses simultaneously, for the one having the experience is a human being and the 
one being experienced by the subject of his experience is also a human being. The human being is simultaneously its subject and object.

The personal subjectivity proper to a human being, therefore, is ironically paradoxical. It is both reducible as an object of experience and irreducible as the subject that possesses its own experience. Wojtyla (1993a, 213) does not see this paradox as an inexplicable antinomy but as two complementary aspects of the one human subject. On the one hand, assuming itself as the subject experienced, the human subject as suppositum is enriched with "in-selfness and inwardness" (Wojtyla 1993b, 223), and its reducibly metaphysical individuality is transformed into irreducibly personal uniqueness. On the other hand, grounding itself on the suppositum as on the metaphysical subject of experience, the human subject of experience is saved from remaining as what the idealists would suppose to be, i.e., a pure floating consciousness.

It should be well noted that Wojtyla's empirical standpoint cannot be simply identified with phenomenalism. For, consciousness in Wojtyla's empirical standpoint is different from that of phenomenalism in at least two ways. First, consciousness for Wojtyla is nailed into concreteness and cut through by metaphysical subjectivity (i.e., the subject as suppositum) such that "the suppositum is the fundamental expression of the whole (conscious) experience of the human being... this expression is in some sense an inviolable one: experience cannot be detached from it" (Wojtyla 1993b, 223). Now, it is true that Wojtyla takes the metaphysical subjectivity as not "beyond-thephenomenal" or "extraphenomenal," for it enters into the field of conscious experience; the metaphysical subjectivity, however, is not taken to be subsumed into and dominated by consciousness; rather, it is taken by Wojtyla (1993b, 223) as "throughthe-phenomenal" or "trans-phenomenal." It delimits all conscious experiences as $m y$ experiences (Cf. 1993b, 223) on the one hand, and on the other hand, it functions as the ontic root of all dynamisms of human beings that enter into consciousness (Cf. Wojtyla 1979, 75). Second, Wojtyla rightly deprives consciousness of its phenomenalists' function of constitution and delimits consciousness as but one aspect of man. In effect, what enters into consciousness is not subjectively constituted by consciousness but objectively recognized by human cognition. Wojtyla $(1979,35)$ writes, "The meanings of things and their relations are given to consciousness, as it were, from outside as the product of knowledge (i.e., as constituted by cognition)." Accordingly, "It is self-knowledge that contributes to the formation of self-consciousness" (Wojtyla $1979,39)$. It would mean that consciousness is saved from "an unending sequence of 'self-subjectivations' or self-constitutions, rather, it is firmly established and ascertained in the really grounded existence of man through self-knowledge (Cf. Wojtyla 1979, 37).

Nevertheless, Wojtyla still affirms that consciousness with its reflective and reflexive functions "has an essential significance for asserting man's subjectivity, because it is consciousness that allows man to experience himself as the subject" (Wojtyla, 1979, 57). In a nutshell, Wojtyla's philosophy of the human person comes as a result of phenomenological enrichment of the metaphysical person on the one hand, and on the other hand, as a result of metaphysical concretization of the phenomenological person. 
After these preliminary clarifications, it is easier to go into the core of Wojtyla's philosophy of the human person, i.e., the notion of dynamism. Wojtyla (1993b, 221) notes, "in experience, the human being is given to us as someone who exists and acts." First of all, this data of experience can be generally objectified as the dynamism of the human being, analogical to "the dynamism of all beings" (Wojtyla 1979, 63). It is this overarching idea of dynamism that provides the storyline for Wojtyla to articulate his understanding of the total subjectivity of the human being (as both metaphysical and phenomenological). Specifically, human being for Wojtyla is, first of all, a "dynamic subject" that not only exists but also manifests its own dynamism in twofold structures that have the experience of efficacy (i.e., the experience of "being the agent") as their demarcation line. Wojtyla (1979, 66-67) writes,

On the one hand, there is that form of the human dynamism in which man himself is the agent, that is to say, he is the conscious cause of his own causation; this form we grasp by the expression, "man acts." On the other hand, there is that form of human dynamism in which man is not aware of his efficacy and does not experience it; this we express by "something happens in man."

For Wojtyla, accordingly, the human person is not so properly a dynamic subject as an acting person. In particular, although Wojtyla (1993b, 224) concedes that "a complete analysis of human dynamism would give us a complete picture of human subjectivity," he considers human action as the precise point where the human person discloses itself by constituting itself as "a human self" (1993b, 225). Put differently, though the metaphysical subjectivity, or the human suppositum, is the root wherefrom "springs forth not only the dynamism of what happens in man, but also the total dynamism of acting" (Wojtyla 1979, 75), the metaphysical person is still to disclose himself and emerge as a personal self (Cf. 1993b, 225), and this happens through action.

For, when I act, I experience myself as dynamized or activated on the one hand, and on the other hand, I also experience myself as the cause of my own dynamization or activation (Cf. Wojtyla 1979, 68). In other words, while acting, I am not simply the cause of my actions (i.e., I am not simply an actor), efficacy in this sense alone "does not tell us the whole story about personal subjectivity" (Wojtyla 1993b, 229). In fact, being caused by me, my actions do not simply come out of me but also simultaneously come back to me and determine myself. Put differently, the fact of my being an actor aims first not to the external object of my action but refers firstly to me myself. Thus, Wojtyla (1993b, 230) writes,

In human activity or action, I turn toward a variety of ends, objects, and values. In turning toward those ends, objects, and values, however, I cannot help but also in my conscious activity turn toward myself as an end, for I cannot relate to different objects of activity and choose different values without thereby determining myself (thus becoming the primary object for myself as a subject) and my own value. The structure of human action is autoteleological in a special dimension. 
In short, my efficacy (as an agent) is also my self-determination. This efficacy as self-determination (or self-determinating efficacy), for Wojtyla (1993b, 230), "fully discloses the person as a subjective structure of self-governance and self-possession." In fact, this subjective structure is somehow realized anew in every efficacious act of self-determination (See Wojtyla 1993b, 231). Moreover, thanks to the reflexive function of consciousness, the determined self (or the realized structure of self-governance and self-possession) is experienced and interiorized as the very "inwardness" and "inselfness" of the acting person, i.e., the very personal subjectivity of the human self(See Wojtyla 1993b, 231).

Wojtyla, however, is also very precautious in specifying further that the personal self is "not reducible to consciousness alone," he maintains that it is constituted "through consciousness" or that consciousness is only the path of the person's selfconstitution. In effect, "the real constitution of this self... ultimately takes place as a result of acts of self-determination" (Wojtyla 1993b, 231). Put differently, "I experience myself as a personal subject to the extent that I become aware that I possess myself and govern myself' (Wojtyla 1993b, 231). Thus, to capitulate the total personal subjectivity proper to man, Wojtyla (Wojtyla 1993b, 231) writes: "The self is nothing other than the concrete suppositum humanum, which, when given to itself by consciousness (self-consciousness) in the lived experience of action, is identical with the self-possession and self-governance that comes to light as a result of the dynamics of the personal efficacy that is self-determination."

Dwelling more on efficacy as self-determination, Wojtyla $(1979,68)$ expansively discovers that "the efficacy of man draws him, on the one hand, into that form of his dynamism which consists in acting and, on the other, it allows him to remain above this dynamism and this acting." Human efficacy as self-determination, therefore, makes further twofold revelations of the human person. On the one hand, the human person is himself returned to, activated, and determined in his efficacy; there is thus "the immanence of man in his own acting" (Wojtyla 1979, 68). On the other hand, since this immanence is formed in the very process of self-determination, self-determination discloses the somewhat incompleteness of the person and completes his tendency toward his own fulfillment (See Wojtyla 1993b, 233). In fact, Wojtyla somehow equates selffulfillment with self-determination, i.e., with the realization of the personal structure of self-possession and self-governance: "to fulfill oneself means to actualize, and in a way to bring to the proper fullness, that structure in man which is characteristic for him..., the structure of self-governance and self-possession" (Wojtyla 1979, 151).

However, having himself turned to, activated, determined, and thus somewhat fulfilled, the self in his efficacy is not constituted as "a closed-in structure" (Wojtyla $1993 b, 235)$. Instead, the immanent self that arises in efficacy reveals at the same time "the most expansive openness of the subject toward reality," i.e., reveals itself as with transcendence. Now, if transcendence in metaphysics signifies "being as a reality surpassing all categories, while at the same time constituting their foundation" and also signifies in particular "the true and the good as transcendentals on the same level as being;" it can then generally be said to signify a surpassing, i.e., a going-out-beyond or a rising-above (Wojtyla 1993b, 233). Concretely, it makes a subject able to have an expansive appreciation of being as true and good while at the same time retains the 
subject from being thereby absorbed. Thus, by virtue of his own transcendence, the subject can horizontally transgress his own limits in his action of knowing the truth or willing the good, and can also vertically rise above himself and remain free with regard to the very process of knowing the truth or willing the good (See Wojtyla 1979, 119). In short, therefore, it is a transcendence characteristic to the person that creates the expanse wherein his efficacy as self-determination becomes possible. As Wojtyla would say, "transcendence is the spirituality of the human being revealing itself" (Wojtyla 1993b, 234).

Transcendence, nevertheless, is, in turn, only expressed by and realized in, the person's self-determination, which is further identified by Wojtyla as freedom. Now, since "freedom (for Wojtyla) is realized precisely through the willing and choosing of a true good" (Wojtyla 1993b, 234), the person's authentic transcendence is expressed only in a healthy conscience that enables the willing and choosing of a "true good" through its proper function of subordinating the good to the true. In the last analysis, therefore, it is not pure efficacy as self-determination in action that fulfills the self, but a transcendence toward the true good revealed in efficacy as self-determination that truly fulfills the self, such that "without this transcendence - without going out beyond myself and somehow rising above myself in the direction of truth and the direction of a good willed and chosen in the light of truth - I as a person, I as a personal subject, in a sense am not myself" (Wojtyla 1993b, 234). ${ }^{2}$ In fact, it is not difficult to push further in saying that failure in authentic transcendence is the unfulfillment of the personal self and amounts to a denial or rejection of the ontic structure of the personal subjectivity. It is in this sense that, returning to where Wojtyla's analysis of the person starts, i.e., action, Wojtyla $(1979,151)$ remarks:

Human actions once performed do not vanish without a trace: they leave their moral value, which constitutes an objective reality intrinsically cohesive with the person, and thus a reality also profoundly subjective. Being a person man is "somebody," and being somebody he may be either good or bad.

Wojtyla's philosophy of the human person, therefore, is not an indifferent one. Rather, the human person is treated as a dynamic subject, an acting person, or, more precisely, a transcendent subject that activates itself by self-determination, and thus an essentially moral subject wherein the metaphysical person is not left morally untinged. The phenomenological person becomes something definite and thus morally responsible. All these elements of Wojtyla's philosophy of the human person will merge and form the basis of the personal significance of the human body.

\section{THE PERSONAL SIGNIFICANCE OF THE HUMAN BODY}

Before venturing into Wojtyla's discussion of the personal significance of the human body, it is beneficial to point out that he distances himself away from certain phenomenalists' view of the body that developed in the post-Cartesian philosophy. For Wojtyla (1993c, 169), Descartes splits the human being into "an extended substance 
(the body) and a thinking substance (the soul)," having the body running parallel with the soul and no longer forming with the soul into "one substantial compositum humanum." Gradually, the thinking substance is treated by certain phenomenalists as a kind of hypostatized consciousness, somehow identifiable with the person who exists against the background of the body as against a mere organism. In effect, the person becomes merely "an object of inner experience," whereas the body, somehow outside the person, is "like all other bodies in the natural world," "accessible to observation and (mere) external experience." Wojtyla is aware of the distinction between the body and the human person as overemphasized by certain post-Cartesian phenomenalists. Like those phenomenalists, Wojtyla (Wojtyla 1979, 205) affirms that "the person is not to be identified solely with the body as such;" unlike them, however, Wojtyla also affirms vigorously the personal significance of the body through his notion of "the integration of the person in action."

Derived from the Latin adjective integer, which means whole or complete, the term "integration" for Wojtyla denotes the wholeness of a thing. Yet, the wholeness denoted by the term integration does not simply entail any aggregation of previously disconnected parts, but "a unity emerging on the basis of some complexity" (Wojtyla $1979,191)$. In effect, the human person is not a pure consciousness accidentally connected with a body as with an alien part; rather, as Aguas $(2014,126)$ notes, though the person can be "viewed as having different aspects, the physical, intellectual, emotional, social, spiritual," the person manifests itself as "a dynamic unity of all these complex aspects in his actions." To be more specific, Wojtyla $(1979,190)$ sees "the integration of the person in action" as complementary to the notion of "the transcendence of the person in action." As has been discussed, transcendence is possible and realizes itself through the person's efficacy as self-determination in action (as of now, let us set aside the element of freedom), i.e., through the very revelation and realization of the person's structure of self-possession and self-governance. In a sense, transcendence is the very emergence of the acting self, the rising up of what is immanent of the person in action. As Wojtyla often repeats, "the transcendence proper to the experience had in being the agent of acting passes into the immanence of the experience of acting itself' (1979, 68; see also 191-192. Emphasis added). In other words, the very experience of transcendence passes into the within and, as it were, forms the very structure of personal immanence. The structure of the personal immanence formed, however, is not formed by the experience of transcendence alone, but together with the experience of something else. For, "when I act, I am wholly engaged in my acting, in that dynamization of the ego to which my own efficacy has contributed" (Wojtyla 1979, 68, 192). The experience of transcendence is not identical with the immanent self, for it only contributes a part to the total dynamization of the ego that integrates itself through action.

Specifically, the total dynamization of the ego (i.e., the immanent self-formed) includes not only the active dynamism of transcendence but also the passive dynamisms involved in the action. For, in action, what is given in experience is not simply my own efficacy as self-determination (i.e., the realization of self-governance and selfpossession); what happens in me is also experienced by me as my dynamism (See Wojtyla 1979, 191). To argue more forcefully, Wojtyla $(1979,190)$ writes, "there is 
no governing of oneself without subjecting and subordinating oneself to this governance; neither is it possible to have active possession of oneself without a passive response in the dynamic structure of the person." Thus, the integration in the total dynamization of ego does not mean a simple putting together of the twofold dynamisms, but a kind of essential union of the two into one dynamism, i.e., the dynamism of the person. In other words, both the active spiritual dynamism and the somatic (and psychic) reactive dynamisms, though mutually distinctive, form but one dynamism of the person in action (Cf. Aguas 2014, 125-127). Accordingly, the personal significance of the body lies in that its reactive dynamism as being integrated in and making up the one dynamism of the person in action, together with the active dynamism of the person.

The active dynamism of the person, of course, still holds the upper-hand in the total dynamism of the acting person:

It is in action that the whole psychosomatic complexity develops into the specific person-action unity.... Action comprises the multiplicity and diversity of the dynamisms that belongs to the soma and the psyche. In relation to them, action constitutes superior dynamic unity. This is, in fact, what the integration of the person in the action - as the complementary aspect of transcendence - consists in; for the human action is more than a sum of those other dynamisms; it is a new and superior type of dynamism, from which the others receive a new meaning and a new quality that is properly personal. They do not possess this meaning and this quality on their own account and, insofar as they are but the natural dynamism of the psyche and the soma, they attain these only in the action of the person (Wojtyla 1979, 197).

Thus, the somatic reactive dynamism, identified by Wojtyla as "the body as such" $(1979,208)$, is properly personal through the notion of integration, i.e., through the fact that it is being integrated into one personal dynamism of the person in action. Nevertheless, though Wojtyla sees the body as attaining its personal significance from the dynamic unity of the person constituted by action, the body is not understood by him as simply passive or simply subsumed into the integration of the person. Rather, the body also has a determinative role for the very integration of the person: "the person's integration in the action rests on the conditioning... by the somatic; it is from this conditioning that man's integrity is derived" (Wojtyla 1979, 202). Thus, the body or the somatic dynamism is not simply one passive part of the total dynamism of the person in action; it somehow actively conditions the very integration of the acting person. This general understanding of the body's personal significance makes ready a more specific analysis of the body's personal significance in Wojtyla's philosophy of the human person.

To speak more specifically about the personal significance of the body, Wojtyla firstly starts with an assertion that "it is the body that gives man his concreteness" (1979, 203). The concreteness given by the body is analyzable on two levels: on the one hand, the body is the source of the person's metaphysical individuation; on the other hand, it is also the source of the phenomenological embodiment of the person. In effect, what the body contributes is "the specific, strictly individual build" or "constitution" of the person 
(Wojtyla 1979, 204). It means that the concreteness derived from the body entails not simply the tangibility of the human being but the very uniqueness of the human person. Accordingly, it is in the body that the human person concretizes and expresses its uniqueness. In the words of Wojtyla $(1979,204)$, "the human body is in its visible dynamism the territory where, or in a way even the medium whereby, the person expresses himself." In short, the body concretizes the external expression of the unique person.

In fact, the body does not simply concretize the external appearance of the unique person; it further (and secondly) concretizes the internal dynamic realization of the human person as unique. Wojtyla $(1979,205)$ writes, "the body is the territory and, in a way, the means for the performance of an action and consequently for the fulfillment of the person." Specifically, as already discussed, the person in action is the primary object of his own action, for he determines himself in his action. This presupposes that he himself is objectified in his action. In his self-objectification, however, "the body participates in a special manner." For, Wojtyla $(1979,206)$ argues:

Whenever the person externalizes himself by means of the body, he becomes simultaneously the object of his acting. The objectification of the body then becomes an integral element in the objectification of the whole personal subject, to whom the body "belongs," and of whose subjectivity it forms a structural part.

Thus, it is mainly through objectifying the body that the human person objectifies himself and thereby experiences his own subjectivity as a spiritual subjectivity that comprises his body into its very internal structure. Of course, the body is not identified with the very subjectivity of the person, for "man is not the body; he only has it" (Wojtyla 1979, 206). Yet, it is precisely this non-identity of the body with the person that enables the emergence of the integral subjectivity of the person. For, as Wojtyla $(1979,206)$ writes, "man as the person 'possesses himself' in the experience of his embodiment precisely because it entails the feeling of possessing his body, and he governs himself because he controls his body." 3 Thus, the body, as it were, consolidates and even fills up with tangible content, the very structure of the person's subjectivity.

Still more (and thirdly), the body also concretely plants the person in nature and sets the person as concretely belonging there. In other words, the body not only makes the person partake in nature but also conditions the person to be similar to the rest of nature. Accordingly, like the rest of nature, the human body is defined by Wojtyla in terms of reactivity and is attributed a kind of autonomy to the body: "Reactivity" would refer to the human body as such" and "the dynamism of the human body as such does not depend on the self-determination of the person. It is instinctive and spontaneous" (Wojtyla 1979, 208, 210). This instinctive autonomy or subjectivity of the body, however, “by no means contradicts man's personal unity; on the contrary, in its own way, it is a characteristic of this unity" (Wojtyla 1979, 211). The body is, as it were, "a basis, an underlayer, or a substructure..., intrinsically built into the personal structure of man's unity" (Wojtyla 1979, 211). Thus, instead of parallelism, there is an interrelation between body and person. 
When viewed from the side of the person, the person is tinged by the body. For, the reactive dynamism of the body somehow permeates the person and becomes "very deeply rooted in all human acting" (Wojtyla 1979, 208). As Wojtyla $(1979,208)$ writes, "there is no doubt that the term 'reaction' can be adequately applied to various obviously differentiated components of human behavior and modes of acting," including even "(the) definite response of the will to a presented value." In short, the body "seems to determine the integrity of this complex being (i.e., a person in action)" (Wojtyla 1979, 211). Seen from the side of the body, however, the body seems to be in turn tinged by the active dynamism of the person. For the autonomy or subjectivity of the body, "in its reactivity, with the specific ability to transform stimulations into motor impulses," is such autonomy or subjectivity that it is compliant to the person's use in acting and that it is also synthesized in the person's action (Wojtyla 1979, 214). Wojtyla $(1979,214)$ notes further that the synthesis can become "so spontaneous and fluent that in most cases, we never notice the causative effect of the will in the synthesis of actions and motions... Habitual motions are made as if the will did not enter into play." To a certain extent, the body in its reactiveness may even play "an active role in self-determination (as a synthesized action of the person)" (Wojtyla 1979, 199). In short, therefore, the body is so much in tune with the person that, in itself, it can already be said as a quasi-person and thus very significantly personal.

Before concluding this study, it is also important to notice that, since the human person is considered by Wojtyla as essentially a moral subject, the human body is accordingly also morally significant. This is clearly not a problem when the subjectivity or autonomy of the body is consciously under the control of the acting person. With regard to bodily instincts, the instincts of self-preservation and reproduction in particular, or even the body's habitual motions, which is tantamount to be what simply happens in man, Wojtyla $(1979,199)$ is aware that "it is a different question whether they can be treated as mere impulses, whether the efficacious engagement of the will played its part." However, he is clear that they cannot be reduced to be simply somatic but constitutes "a dynamic trait of the human being and existence as a whole" (Wojtyla $1979,217)$. Thus, they bear in themselves the very direction to the objective value of the person and the objective value of the ends of the person in action. This is precisely the position chosen by Wojtyla $(1979,219)$ :

These considerations suggest that the problem of instincts, here limited to two examples, is not a purely somatic one, even though both the instincts of self-preservation and sex are rooted deep within the human body and its natural reactivity. Does the significance of the instincts in the person derive first of all from the subjective force of those somatic reactions as such which are liberated because of instincts, or is it rather the outcome of the objective value of the ends, to which man is urged and directed by instincts? ... it seems more plausible to accept the latter alternative.

Thus, the body's personal significance is also shown by its morally tinged characteristic, which does not simply comprehend those bodily dynamisms that come under the conscious control but also the body's habitual motions and even its instincts. 


\section{CONCLUSION}

Seeing the human person as a dynamic subject, or more specifically as an acting person, and thus, through its transcendence, also as self-determinative and essentially moral, Wojtyla is able to understand the human body from a larger perspective as personally significant. In general, the body for Wojtyla is not "outside" the person that runs parallel to it; instead, it is integrated with the active dynamism into the one dynamism of the person. Though the body attains its personal significance from the dynamic unity of the person as constituted by action, the body is not simply subsumed by the person; rather, it conditions the person by concretizing it.

This entails three specific points. First, the body concretizes the external appearance of the person as a metaphysical individual and a phenomenologically unique "constitution." Second, the body also concretizes the person's internal dynamic realization; in a sense, the body consolidates and even fills up with tangible content, the very structure of the person's subjectivity. Third, the body, as a reactive dynamism, so tinges the person as to condition the very integration of the person and is also itself so tinged by the person as somewhat active in its corporation in the person's action and thus can be called, in itself, as a "quasi-person." As a sub-point of the third specific point, the body, even in its instincts, bears the direction to the objective value of the person or the objective value of the end of the acting person. Accordingly, the human body is also personally significant as being characteristically moral. With all the above considerations, it can be concluded that, for Wojtyla, no investigation of the body is legitimate if it simply relegates the human body as an organism, and that, to be legitimate and truly significant, all studies of the human body have to start from, or at least presume, the personal significance of the body.

\section{NOTES}

1. The expression "extraphenomenal" is used by Peter Emmanuel A. Mara (2007, 91).

2. For a brief discussion on this point, see Jaroslaw Kupczak $(2000,127)$.

3. This point is also touched upon in Rocco Buttiglione $(1997,159)$.

\section{REFERENCES}

Aguas, Jove Jim S. 2014. Person, action and love: The philosophical thoughts of Karol Wojtyla (John Paul II). Manila: UST Publishing House.

Buttiglione, Rocco. 1997. Karol Wojtyla: The thoughts of the man who became Pope John Paul II. Grand Rapids, Michigan: WB. Eerdams Publishing Co.

Bynum, Caroline. 1995. Why all the fuss about the body? Critical Enquiry 22, (1): 133. DOI: $10.1086 / 448780$.

Diemling, Maria and Giuseppe Veltri (Editors). 2009. The Jewish body: Corporeality, society, and identity in the Renaissance and early Modern Period. Leiden·Boston: Brill. 
Kupczak, Jaroslaw. 2000. Destined for liberty: The human person in the philosophy of Karol Wojtyla. Washington, D.C.: Catholic University of America Press.

Mara, Peter Emmanuel A. 2007. Understanding man as a subject and a person: A Wojtylan personalistic interpretation of the human being. Kritike: Online Journal of Philosophy. 1, (1): 86-95. 86-95. DOI: 10.3860/krit.v1i1.552.

Robb, John and Oliver J. T. Harris (Editors). 2013. The Body in history: Europe from the Palaeolithic to the future. New York: Cambridge University Press.

Schmitz, Kenneth L. 1993. At the center of human drama: The philosophical anthropology of Karol Wojtyla. Washington, D.C.: Catholic University of America Press.

Wojtyla, Karol. 1979. The acting person. Translated by Andrej Potocki. Dordrecht: D. Reidel Pub. Co.

Wojtyla, Karol. 1993a. Subjectivity and the irreducible in the human being. In Person and Community: Selected Essays. Translated by Theresa Sandok. New York: Lang, pp. 209-217.

Wojtyla, Karol. 1993b. The person: Subject and community. In Person and Community: Selected Essays. Translated by Theresa Sandok. New York: Lang, pp. 219261.

Wojtyla, Karol. 1993c. Thomistic personalism. In Person and Community: Selected Essays. Translated by Theresa Sandok, New York: Lang, pp. 165-175. 